\title{
MANAJEMEN SELEKSI INDUK DALAM PEMBENIHAN IKAN CUPANG DI SMK NEGERI 1 MEUREUBO ACEH BARAT
}

\section{PARENT SELECTION MANAGEMENT IN CUPANG FISH SEEDLINGS IN SMK NEGERI 1 MEUREUBO ACEH BARAT}

\author{
Fazril Saputra $^{1 *}$, Citra Dina Febrina ${ }^{1}$, Dini Islama ${ }^{1}$ \\ ${ }_{1}^{1}$ Program Studi Akuakultur, Fakultas Perikanan dan IImu Kelautan, Universitas Teuku Umar, Meulaboh, \\ Indonesia, 23615 \\ *Korespondensi: fazrilsaputra@utu.ac.id
}

\begin{abstract}
ABSTRAK
Pengabdian ini bertujuan untuk memberikan pengetahuan kepada siswa/i SMK Negeri 1 Meureubo Aceh Barat tentang manajemen seleksi induk pada kegiatan pembenihan ikan cupang. Ikan cupang adalah salah satu jenis ikan hias yang sangat populer dikalangan masyarakat mulai dari kalangan atas maupun kalangan bawah serta dari anak-anak sampai dewasa. Jika dilakukan dengan serius, budidaya ikan cupang memiliki prospek yang cerah dan mampu meningkatkan pendapatan masyarakat. Budidaya ikan cupang dapat berjalan dengan modal yang minim tetapi menghasilkan profit yang menjanjikan. Namun dalam membudidayakan ikan cupang, banyak juga pembudidaya yang menemui berbagai kendala terutama bagi pemula. Salah satu kendala yang ditemui dalam budidaya ikan cupang adalah pada fase pembenihan. Pada fase ini para pemula kesulitan untuk memilih indukan cupang yang sudah siap untuk dipijahkan. Untuk mengatasi kendala pembenihan ikan cupang pada pembudidaya pemula dilakukanlah program pengabdian kepada masyarakat ini. Solusi yang ditawarkan dari pengabdian kepada masyarakat ini adalah memberikan keterampilan tambahan kepada siswa SMK Negeri 1 Meureubo Meulaboh, Aceh Barat untuk dapat menyeleksi induk pada pembenihkan ikan cupang yang baik dan benar sesuai dengan SNI ikan cupang hias. Metode pengabdian adalah diskusi dan praktek langsung cara menyeleksi induk ikan cupang (Betta sp.) yang baik dan benar. Hasil yang diperoleh dari pengabdian adalah siswa SMK Negeri 1 Meureubo Meulaboh, Aceh Barat sangat antusias untuk membenihkan ikan cupang hias (Betta sp.) dan mengharapkan agar program pengabdian kepada masyarakat ini dapat terus dilaksanakan untuk memberikan pendampingan kepada siswa SMK Negeri 1 Meureubo Meulaboh, Aceh Barat.
\end{abstract}

Kata Kunci : Ikan_Cupang, Manajemen_Seleksi_Induk, Pembenihan

\section{ABSTRACK}

This service aims to provide knowledge to students of SMK Negeri 1 Meureubo, West Aceh about the management of parent selection in betta fish hatchery activities. Betta fish was a type of ornamental fish that was very popular among people from the top and bottom as well as from children to adults. If done seriously, betta fish farming has bright prospects and can increase people's income. Betta fish farming can run with minimal capital but produces promising profits. However, in cultivating betta fish, many cultivators encounter various obstacles, especially for beginners. One of the obstacles encountered in the cultivation of betta fish was the hatchery phase. In this phase, beginners find it difficult to choose hickey sires that were ready to be spawned.To overcome the obstacles of hatching betta fish for novice cultivators, this community service program was carried out. The solution offered by this community service was to provided additional skills to students of SMK Negeri 1 Meureubo Meulaboh, West Aceh to be able to select broodstock for good and correct betta fish breeders in accordance with SNI for ornamental betta fish. The service method was a discussion and direct practice of how to select the correct and correct parent betta fish (Betta sp.). The results obtained from the dedication are that the students of SMK Negeri 1 Meureubo Meulaboh, West Aceh were very enthusiastic about breeding ornamental betta fish (Betta sp.) and hope that this community service program can continue to be implemented to provide assistance to students of SMK Negeri 1 Meureubo Meulaboh, Aceh West.

Keyword: Betta_Fish, Parent_Selection_Management, Seeding 


\section{PENDAHULUAN \\ Latar Belakang}

Budidaya ikan hias semakin diminati oleh masyarakat dari tahun ke tahun. Budidaya ikan hias memiliki prospek yang mengiurkan karena ikan hias dapat memberikan nilai ekonomis walaupun hanya dilakukan dilahan sempit dengan jumlah air terbatas (Lesmana dan Dermawan, 2001). Pada tahun 2010 Ikan hias yang diperdagangkan di dunia mencapai 1.600 jenis, di mana 750 jenis di antaranya adalah ikan air tawar (Kusrini, 2010). Tingginya nilai perdagangan ini telah mendorong meningkatnya kebutuhan ikan hias baik di dalam maupun di luar negeri, sehingga perkembangan usaha budidaya ikan hias terus ditingkatkan dari segala aspek. Beberapa alasan masyarakat memelihara ikan hias yaitu sebagai hiasan di rumah, aktivitas hiburan, mengurangi stres dan harga ikan hias yang sangat variatif dan terjangkau menjadi pendorong minat masyarakat untuk memelihara ikan hias(Iskandar, 2004).

Popularitas ikan hias semakin meningkat dengan diselenggarakan kegiatan pameran dan kontes ikan hias mulai dari tingkat lokal, nasional dan internasional. Berdasarkan data badan perdagangan dunia 2013, khusus nilai perdagangan ekspor ikan hias pada beberapa tahun mengalami tren positif dan menjadikan Indonesia sebagai negara pengekspor ikan hias terbesar urutan nomor 5 dunia. Setiap pelaku pembudidaya dapat memproduksi ikan hias air tawar berkisar antara 1.000-10.000 ekor setiap bulan yang diusahakan di atas lahan mulai dari $30 \mathrm{~m}^{2}-200 \mathrm{~m}^{2}$ dengan keragaman beberapa spesies meliputi ikan black ghost, cupang, discus, gupi, louhan, maskoki, manfish dan ramiresi. Budidaya ikan dapat dilakukan di perkotaan yang dikenal sebagai urban fish farming, sehingga dapat meningkatkan produktivitas lahan dan menghasilkan nilai ekonomis (Kordi, 2012).

Salah satu jenis ikan hias yang sangat populer dikalangan masyarakat mulai dari kalangan atas maupun kalangan bawah serta dari anak-anak sampai dewasa adalah ikan cupang. Ikan cupang adalah ikan hias air tawar yang populer dan banyak digemari masyarakat. Perkembangan ikan cupang cukup pesat karena mudah untuk dipelihara (Rachmawati, Basuki dan Yuniarti, 2016). Selain indah dan menarik sebagai ikan hias, ikan cupang juga tangguh sebagai ikan aduan. Ikan ini memiliki beberapa nama/ istilah diantaranya ikan laga atau ikan adu, sedangkan di mancanegara ikan ini dikenal dengan nama fighting fish atau disebut juga ikan petarung. Istilah tersebut berarti sifat petarung dari cupang telah diakui secara luas, dan di kalangan para penggemar atau hobiis ikan hias, cupang telah mempunyai kalangan hobiis tersendiri (Wahyudewantoro, 2017).

Budidaya ikan cupang memiliki prospek yang cerah dalam usaha perikanan serta mampu meningkatkan pendapatan masyarakat. Usaha ini dapat berjalan modal yang minim tetapi profit yang menjanjikan (Saputra dan Efianda, 2018). Namun dalam membudidayakan ikan cupang, banyak pembudidaya pemula yang menemui berbagai kendala. Salah satu kendala yang ditemui dalam dalam membudidayakan ikan cupang adalah pada fase pembenihan ikan cupang. Pada fase ini pembudidaya pemula kesulitan untuk menyeleksi indukan cupang yang sudah siap untuk dipijahkan. Untuk mengatasi kendala tersebut dilakukanlah program pengabdian ini pada pembudidaya pemula. Wilayah yang dipilih untuk melakukan pengabdian kepada masyarakat adalah Wilayah Meureubo. Meureubo merupakan Kecamatan yang terletak di Kabupaten Aceh Barat. Kecamatan meureubo terdiri dari 26 desa dan 8 dusun. Jumlah penduduk 
Kecamatan Meureubo pada tahun 2017 adalah 30.830 Jiwa dengan 15.744 laki-laki dan 15.086 perempuan atau 15\% dari populasi penduduk Kabupaten Aceh Barat. Jumlah pencari kerja tertinggi menurut strata pendidikan yaitu strata sekolah menengah pertama (SMA)/ Sekolah Menengah Kejuruan (SMK)/ sederajat yaitu sebanyak 2810 Jiwa yaitu 2379 pria dan 431 wanita (BPS, 2018). Kecamatan Meureubo memiliki sebuah Sekolah Menegah Kejuruan (SMK) yaitu SMK 1 Meureubo. SMK ini memiliki beberapa bidang minat, salah satu bidang minat yang ada adalah budidaya perairan. Para siswa/i sebagai pembudidaya pemula perlu diberikan ilmu tambahan tentang seleksi induk cupang pada fase pembenihan. Untuk meningkatkan pengetahuan dan keterampilan tambahan pada siswa/i di SMK 1 Meureubo ini dilakukanlah sosialisasi manajemen seleksi induk pada kegiatan pembenihan ikan cupang ini.

\section{Tujuan}

Tujuan kegiatan pengabdian kepada masyarakat ini adalah memberikan pengetahuan kepada siswa/i SMK Negeri 1 Meureubo Aceh Barat tentang manajemen seleksi induk ikan cupang pada kegiatan pembenihan.

\section{Manfaat}

Manfaat kegiatan pengabdian kepada masyarakat ini adalah mampu memberikan skill dan keterampilan kepada siswa/i SMK Negeri 1 Meureubo Aceh Barat untuk membedakan jenis kelamin ikan cupang dan melakukan seleksi induk ikan cupang yang sudah matang gonad untuk dipijahkan.

\section{MATERI DAN METODE PELAKSANAAN Waktu dan Lokasi Kegiatan}

Kegiatan ini dilaksanakan pada tanggal 20 November 2019 bertempat di Sekolah Menengah Kejuruan (SMK) Negeri 1 Meureubo, Meulaboh, Aceh Barat. Objek pada kegiatan ini adalah siswa/i SMK Negeri 1 Meureubo.

\section{Sasaran Pengabdian Masyarakat}

Jumlah peserta yang hadir dalam pelaksanaan pengabdian ini adalah 21 orang. Sasaran dalam pelaksanaan kegiatan pengabdian kepada masyarakat ini adalah siswa/i SMK Negeri 1 Meureubo Aceh Barat kelas 12. Harapan yang ingin dicapai dari pengabdian ini adalah munculnya pemahaman dasar pada siswa/i tentang ciri-ciri induk ikan cupang yang baik dan unggul, serta secara tidak langsung dapat menumbuhkan jiwa kewirausahaan pada siswa SMK Negeri 1 Meureubo Aceh Barat agar dapat melakukan budidaya ikan hias khususnya ikan cupang secara mandiri, sehingga meningkatkan pendapatan siswa secara pribadi maupun kelompok.

\section{Permasalahan Pengabdian Masyarakat}

Ada beberapa permasalahan yang dihadapi siswa/i SMK Negeri 1 Aceh Barat yaitu: (1) Bagi para siswa/i jurusan agribisnis perikanan air tawar SMK Negeri 1 Meureubo Aceh Barat, mereka ingin mendapatkan penghasilan tambahan karena sebagian besar berasal dari keluarga yang kurang mampu, sehingga diperlukan keterampilan lain untuk memperoleh penghasilan tambahan, (2) Siswa/i SMK yang sebagian besar belum memahami teknik seleksi induk cupang yang baik dalam kegiatan pembenihan karena fasilitas yang kurang memadai, sehingga kurang terpacu untuk bisa berwirausaha mandiri dan (3) Pelatihan manajemen seleksi induk ikan 
cupang dalam kegiatan pembenihan ikan cupang ini bisa menjadi solusi bagi siswa/i untuk meningkatkan keberhasilan pembenihan ikan cupang karena menggunakan induk yang baik dan unggul, serta sudah matang gonad untuk dipijahkan.

\section{Metode pelaksanaan dan evaluasi}

Metode pelaksanaan pengabdian masyarakat ini dilaksanakan secara diskusi dan praktek langsung. Pemateri berinteraksi langsung dengan masyarakat pembudidaya ikan dan masyarakat umum. Pemateri memberikan materi dan memberikan contoh langsung cara membudidaya ikan hias cupang yang baik dan benar, kemudian masyarakat dapat praktek langsung cara memelihara ikan cupang hias (Betta sp.) yang baik dan benar sesuai SNI ikan cupang hias (Betta sp.)

Metode evaluasi yang digunakan untuk melihat hasil dari pengabdian kepada masyarakat di SMK Negeri 1 Meureubo adalah dengan menyediakan waktu untuk sesi tanya jawab dan diskusi. Ketika dilakukan tanya jawab dan diskusi ini, siswa SMK diberikan waktu untuk bertanya dan langsung mempraktekkan cara membedakan induk ikan cupang berjenis kelamin jantan dan betina yang baik dan benar, serta cara memilih induk unggul yang siap di pijahkan.

\section{HASIL DAN PEMBAHASAN}

\section{Iptek Yang Ditransfer Kepada Siswa/i}

Pada kegiatan pengabdian kepada siswa/i di SMK Negeri 1 Meureubo dilakukan beberapa tahapan transfer ilmu yaitu :

1. Sosialisasi mengenai manajemen seleksi induk dalam fase pembenihan ikan cupang.

Manajemen seleksi induk dalam kegiatan pembenihan ikan cupang akan dihasilkan benih-benih berkualitas, sehingga nantinya mampu meningkatkan keberhasilan dalam kegiatan pembenihan ikan cupang. Tujuan sosialisasi ini adalah untuk menambah pengetahuan dan wawasan siswa/i SMK mengenai teknik seleksi induk ikan cupang yang unggul, sudah matang gonad dan siap bereproduksi.

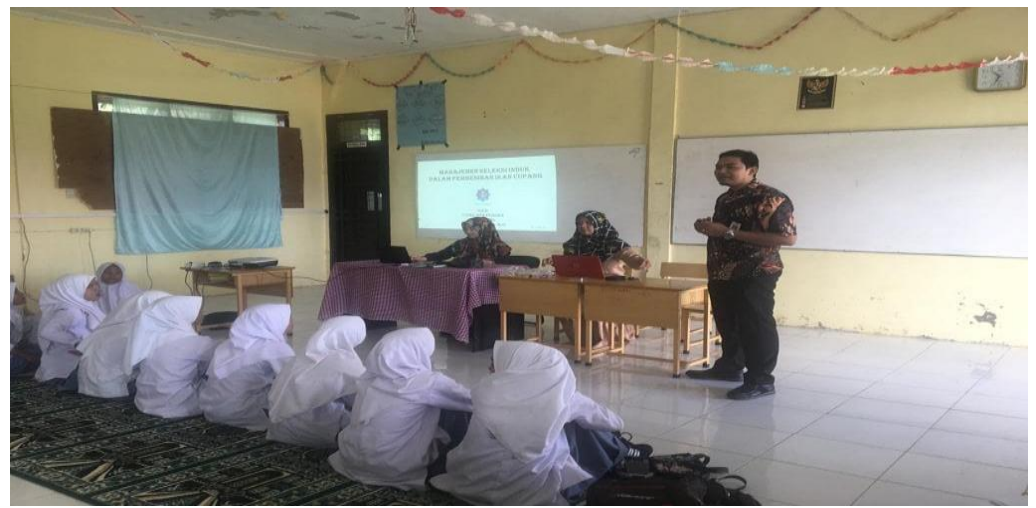

Gambar 1. Sosialisasi mengenai manajemen seleksi Induk dalam fase pembenihan ikan cupang

2. Pelatihan ini juga memberikan bimbingan pembelajaran manajemen dasar budidaya ikan cupang.

Manajemen dasar budidaya ikan cupang sangat menentukan pendapatan dan keberhasilan usaha budidaya ikan cupang. Bimbingan pembelajaran manajemen 
dasar budidaya ikan cupang dilakukan dengan cara mentransfer ilmu kepada siswa/i. Hal ini dilakukan agar siswa/i menjadi wirausaha yang kompeten dan mampu menjalankan usaha budidaya ikan cupang secara berkelanjutan. IImu yang ditransfer kepada siswa/i yaitu sebagai berikut:

a. Perbedaan induk jantan dan betina

Untuk memulai budidaya ikan cupang, langkah pertama yang harus dipersiapkan adalah memperoleh indukan atau bibit berkualitas. Indukan yang baik biasanya berasal dari keturunan unggul, kondisinya sehat, bebas penyakit dan tidak memiliki cacat bawaan. Indukan jantan dan betina harus dipelihara pada wadah terpisah sebelum dipijahkan. Ikan cupang dapat dibedakan berdasarkan tampilan fisik yang dimiliki. Karakteristik ikan cupang jantan yaitu warna tubuh yang cerah, tubuh berbentuk ramping, sirip ekor dan sirip anal panjang. Ikan cupang jantan memiliki pertumbuhan yang lebih cepat dibandingkan dengan cupang betina (Satyani, 2017). Sementara ikan cupang betina memiliki karakteristik warna tubu kurang menarik, perut berbentuk gemuk, ukuran sirip ekor dan sirip anal yang pendek (Nugroho et al., 2020).

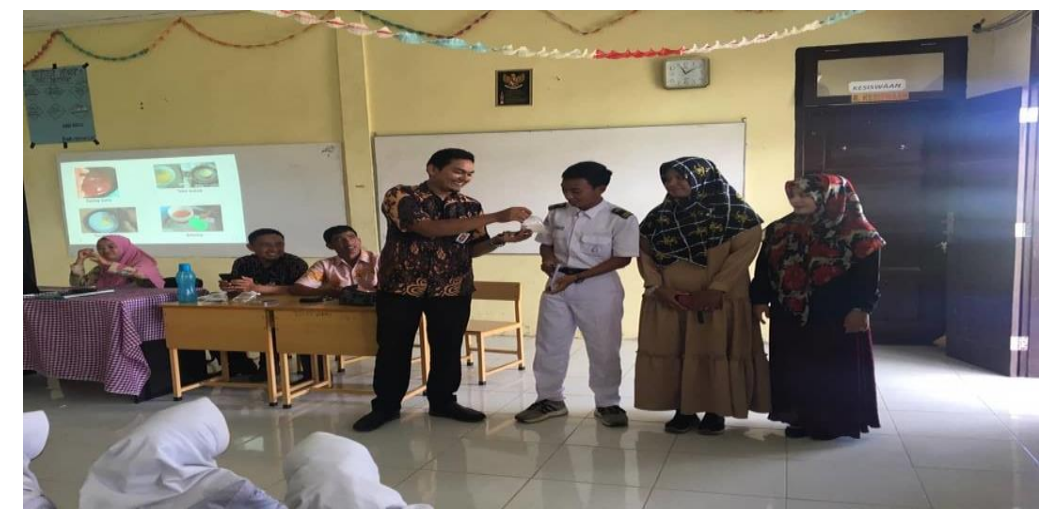

Gambar 2. Pengenalan indukan cupang yang sudah masuk dalam fase matang gonad kepada siswa dan siswi

b. Seleksi induk cupang yang sudah matang gonad

Sebelum pemijahan dilakukan, faktor penting yang harus diperhatikan adalah indukan jantan dan betina sudah masuk dalam fase matang gonad atau siap untuk dikawinkan. Jika induk yang digunakan tidak matang gonad maka kegiatan pembenihan cenderung akan mengalami kegagalan. Pada kegiatan ini, siswa SMK Negeri 1 Meureubo diberikan pengetahuan tentang pengetahuan untuk menyeleksi induk cupang yang sudah matang gonad. Ciri-ciri induk cupang jantan yang telah siap memijah adalah berumur setidaknya 4-8 bulan, bentuk badan panjang, siripnya panjang dan warnanya terang atraktif, serta gerakannya agresif dan lincah. Sedangkan ciri-ciri induk cupang betina yang telah siap memijah yaitu berumur setidaknya 3-4 bulan, bentuk badan membulat, bagian perut sedikit buncit. siripnya pendek dan warnanya kusam tidak menarik dan gerakannya lambat.

c. Manajemen reproduksi ikan cupang

Siswa/i SMK Negeri 1 Meureubo diberikan pelatihan mengenai perkawinan ikan cupang jantan dan betina. Salah satu ciri khusus yang harus dimiliki oleh ikan cupang yang akan kawin adalah ikan hias jantan selain warnanya yang indah, 
siripnya pun panjang dan menyerupai sisir serit, sehingga sering disebut cupang serit. Sedangkan ikan betina warnanya tidak menarik (kusam) dan bentuk siripnya lebih pendek dari ikan jantan. Hal ini penting untuk mengoptimalkan perkawinan ikan cupang.

d. Manajemen pemberian pakan ikan cupang

Siswa/i SMK Negeri 1 Meureubo diberikan pembekalan terkait pemilihan jenis pakan yang tepat untuk pertumbuhan dan perkembangan ikan cupang. Pemberian jumlah pakan yang tepat sangat penting bagi keberhasilan budidaya ikan cupang dikarenakan akan berdampak pada biaya produksi, selain itu pemberian pakan yang berlebih akan berdampak buruk pada kualitas air yaitu peningkatan kadar amonia dan nitrit.

e. Manajemen kesehatan ikan cupang

Siswa/i SMK Negeri 1 Meureubo diberikan sosialisasi berupa materi cara mengidentifikasi jenis penyakit pada ikan cupang, cara pencegahan dan pengobatan dengan bahan alami. Pembudidaya yang mampu mengenali gejala penyakit sangat penting karena dapat melakukan penanganan secara dini sehingga kematian ikan cupang dapatdihindari.

f. Manajemen kualitas air ikan cupang

Siswa/i SMK Negeri 1 Meureubo diberikan pelatihan mengenai pengelolaan kualitas air pada wadah budidaya. Perserta dilatih cara pergantian air dan menjaga kualitas air tetap berada pada kisaran optimal.

g. Edukasi strategi pemasaran

Strategi pemasaran merupakan salah satu faktor penentu keberlanjutan usaha karena tanpa pemasaran yang tepat usaha akan mengalami penurunan omset. Dalam hal ini Siswa/i SMK Negeri 1 Meureubo dilatih untuk menentukan target pasar dan membentuk mitra kerja dengan beberapa penampung atau agen pembeli ikan hias. Selain itu perserta juga dapat aktif di media social untuk mempromosikan ikan cupang hias yang telah berhasil di budidayakan.

\section{Faktor Pendukung Kegiatan Pengabdian Kepada Siswa/i SMK Negeri 1 Meureubo}

Faktor-faktor yang mendukung terlaksananya kegiatan Pengabdian Kepada siswa/i di SMK Negeri 1 Meureubo dengan baik yaitu:

1. Dukungan Kepala Sekolah dan Guru

Adanya pemberian izin dari kepala sekolah untuk kegiatan Pengabdian Kepada Masyarakat di SMK Negeri 1 Meureubo, serta disediakan waktu dan ruang aula sekolah sebagai tempat pelaksanaan merupakan salah satu faktor pendukung kegiatan ini dapat berjalan dengan lancar.

2. Motivasi Siswa

Adanya motivasi dan keingintahuan yang besar dari siswa terhadap cara menyeleksi induk cupang yang berkualitas baik dalam kegiatan pembenihan menjadi salah satu faktor pendukung kegiatan ini, sehingga pada saat sesi pemaparan materi dapat diterima dengan baik dan ramah oleh peserta. Hal ini terlihat dari antusisame peserta pada sesi diskusi. 
3. Respons dan umpan balik dari siswa

Kehadiran siswa/i untuk berpartisipasi langsung di ruang aula sekolah dalam kegiatan Pengabdian Kepada Masyarakat yang bertemakan manajemen seleksi induk ikan cupang juga merupakan faktor pendukung kelancaran kegiatan ini sehingga programprogram yang telah direncanakan dapat terlaksana dengan baik. Siswa juga terlibat aktif dalam kegiatan dan tidak meninggalkan tempat sebelum kegiatan berakhir. Umpan balik dari siswa dapat dilihat dari ketertarikan siswa untuk membudidayakan ikan cupang ini secara mandiri, sehingga diperlukan pengetahuan tentang manajemen seleksi indukdalam pembenihan ikan cupang.

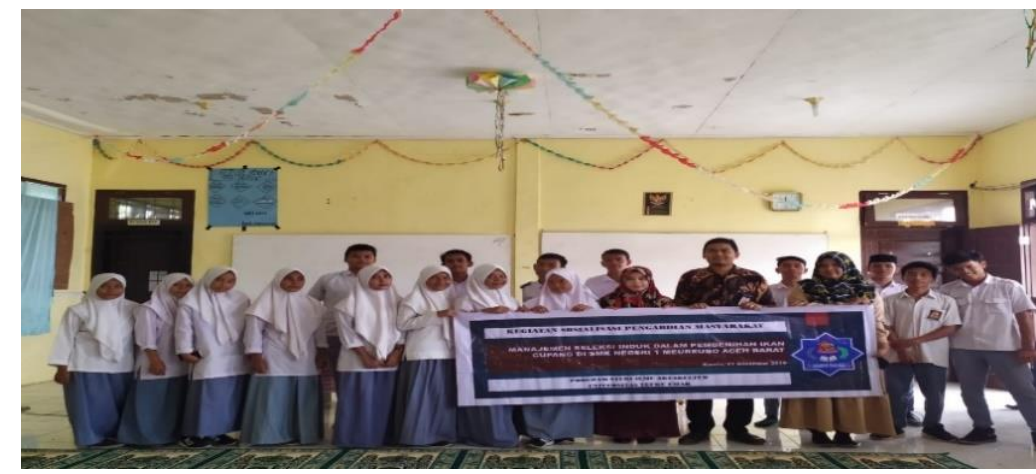

Gambar 3. Foto bersama siswa/i SMK Negeri 1 peserta kegiatan pengabdian

4. Ketersediaan Sarana dan Tempat

Dengan ketersediaan sarana dan tempat kegiatan ini dapat terlaksana dengan baik, dimana kepala sekolah menyediakan aula sekolah sebagai tempat untuk pelaksanaan kegiatan. Selain itu, sekolah juga menyediakan meja dan infokus agar mempermudah penyampaian materi dan transfer ilmu kepada siswa.

\section{SIMPULAN}

Kesimpulan

Adapun kesimpulan yang dapat diambil dari pengabdian ini adalah terjadinya peningkatan pengetahuan manajemen seleksi induk dalam pembenihan ikan cupang yang ditransfer kepada siswa SMK Negeri 1 Meureubo adalah cara membedakan induk jantan dan betina, ciri induk cupang yang telah matang gonad, manajemen reproduksi ikan cupang, manajemen pemberian pakan, manajemen kesehatan ikan, manajemen kualitas air dan edukasi srategi pemasaran ikan cupang.

\section{Saran}

Berdasarkan evaluasi yang telah dilakukan dapat diajukan beberapa saran sebagai berikut:

1. Waktu pelaksanaan kegiatan perlu ditambah agar pemateri dapat memberikan pelatihan langsung di lapangan bagi siswa SMK Negeri 1 Meurebo Aceh Barat tentang teknik seleksi induk ikan cupang, tetapi dengan konsekuensi universitas membantu memberikan biaya pelaksanaan.

2. Adanya kegiatan lanjutan yang berupa pelatihan sejenis yang diselenggarakan secara periodik, sehinga dapat meningkatkan kemampuan dosen dalam melaksanakan pengabdian dan keterampilan masyarakat dalam berbudidaya yang baik dan benar. 


\section{UCAPAN TERIMA KASIH}

Kegiatan sosialisasi manajemen seleksi induk dalam pembenihan ikan cupang dapat diselenggarakan dengan baik dan berjalan dengan lancar sesuai dengan rencana kegiatan yang telah disusun dikarenakan adanya bantuan dan partisipasi dari pihak sekolah dan siswa/i SMK Negeri 1 Meureubo.

\section{DAFTAR PUSTAKA}

BPS, A. B. (2018) Aceh Barat Dalam Angka 2018. Aceh Barat: BPS Aceh Barat.

Iskandar (2004) Panduan Berbisnis Ikan Hias dan Akuarium. Jakarta: Agro Media Pustaka.

Kordi, M. G. (2012) Akuakultur di Perkotaan: Pembenihan, Pendederan dan Pembesaran. Bandung: Penerbit Nuansa Aulia.

Kusrini, E. (2010) "Budidaya Ikan Hias Sebagai Pendukung Pembangunan Nasional Perikanan Di Indonesia," Media Akuakultur. doi: 10.15578/ma.5.2.2010.109-114.

Lesmana, D. S. dan Dermawan, I. (2001) Budidaya Ikan Hias Air Tawar. Jakarta: Penebar Swadaya.

Nugroho, A. A. et al. (2020) "Interaksi Tingkah Laku Ikan Cupang Jantan dan Betina (Betta Splendes) Pada Masa Kawin," Science Education and Application Journal. doi: 10.30736/seaj.v2i1.186.

Rachmawati, D., Basuki, F. dan Yuniarti, T. (2016) "Pengaruh Pemberian Tepung Testis Sapi dengan Dosis yang Berbeda terhadap Keberhasilan Jantanisasi Pada Ikan Cupang (Betta sp.)," Journal of Aquaculture Management and Technology, 5(1), hal. 130-136.

Saputra, F. dan Efianda, T. R. (2018) "Pelatihan Manajemen Pemeliharaan Ikan Cupang Sebagai Ikan Hias yang Berpotensi Meningkatkan Pendapatan Masyarakat," II(1), hal. 44-49.

Satyani, D. (2017) "Pengaruh Umur Induk Ikan Cupang (Betta sprenden regan) dan Jenis Pakan Terhadap Fekunditas dan Produksi Larvanya," Jurnal Penelitian Perikanan Indonesia. doi: 10.15578/jppi.9.4.2003.13-18.

Wahyudewantoro, G. (2017) "Mengenal Cupang (Betta spp.) Ikan Hias yang Gemar Bertarung," Warta Iktiologi, 1(1), hal. 28-32. 